CASE STUDY

\title{
Digital Studio Tutors as Partners
}

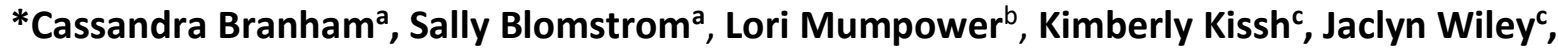 \\ Yunxiao Liuc, Kody Millerc, Zachary Bryant', and Brian Reedyc \\ aDepartment of Humanities and Communication \& Digital Studio Director, Embry-Riddle \\ Aeronautical University, United States of America \\ ${ }^{b}$ Center for Teaching and Learning Excellence, Embry-Riddle Aeronautical University, United \\ States of America \\ 'Digital Studio Tutor, Embry-Riddle Aeronautical University, United States of America.
}

Contact: $\underline{\text { branhac1@erau.edu }}$

\section{ABSTRACT}

This case study examines an initiative at a STEM-focused university where a Digital Studio was developed in response to a perceived lack of digital literacies among students. Digital Studio tutors partnered with faculty, students, and the Center for Teaching and Learning Excellence to improve instruction and enhance students' communication and digital literacy skills. Digital Studio tutors acted as partners in several ways, including developing training materials, conducting on-campus outreach, and contributing to curriculum development and content delivery in a public speaking course. Ultimately, we observed that Digital Studio tutors operated as partners through making suggestions based on their interactions with students that resulted in constructive improvements to curricula and pedagogy. The tutors' skills, knowledge, and approaches complemented those of the faculty member to help students achieve the course learning outcomes. Tutors and the faculty director also enhanced their own digital literacy skills through their involvement in the Digital Studio.

\section{KEYWORDS}

students-as-partners, peer tutoring, digital literacies

This paper presents a project at a STEM-focused university where Digital Studio (DS) peer tutors offer support to students, faculty, and staff in the development of digital literacies with the goal of facilitating STEM communication. The tutors described in this case study are undergraduate students who work as peer tutors and are paid hourly wages as student employees. Digital Studio tutors must demonstrate advanced understanding of digital literacies 
and digital design concepts and software, and Digital Studio tutoring is a supplement to, rather than a replacement of, in-class instruction from faculty. The tutors partnered with faculty and the Center for Teaching and Learning Excellence (CTLE) to improve instruction and enhance students' communication and digital literacy skills. Throughout this process, tutors were partners of the faculty director of the DS, CTLE, the course instructor, and the students. Figure 1 positions the DS tutors as partners of CTLE, faculty, and students. This paper, co-authored by the DS faculty director, the CTLE director, a faculty member teaching a public speaking class, and six DS tutors, not only examines our work with students as partners and the rich relationships the tutors developed, but also extends our work through the practice of collaborative writing on the scholarship of teaching and learning.

Figure 1: Tutors as partners with faculty, CTLE, and students

\section{Teachers}

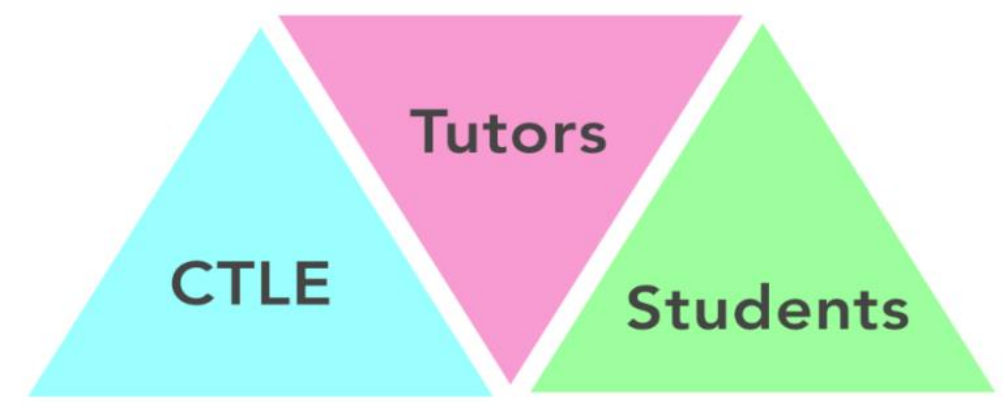

\section{BACKGROUND}

In their 2016 Horizon Report, the New Media Consortium named improving digital literacies as an important challenge for higher education institutions, and research suggests that while students are often comfortable using technology, their knowledge of the technology may lack depth (Oblinger \& Oblinger, 2005). Thus, while students possess functional digital literacy skills, and are often both producers and consumers of digital media, they may lack the critical digital literacy skills necessary to produce and consume media in beneficial and responsible ways. ${ }^{1}$

Our university is one of the world's oldest and largest fully accredited universities specializing in aviation and aerospace. Students are highly motivated with strong technical backgrounds, yet faculty expressed concerns that students lacked the sophisticated digital communication skills necessary for communicating scientific information, both within their disciplines and to the public. Specifically, faculty shared concerns that students in capstone 
courses $^{2}$ had not mastered the essential digital presentation skills that they would later need in the workforce.

In response, a Digital Literacies Initiative began in 2014, focusing on faculty development, student support, and campus outreach. The student support effort centered on providing a tutoring space where students would have access to digital production technologies and where tutors would help students build digital literacy skills. Moving beyond technology training, tutors would partner with students to build skills that would allow students to make sophisticated choices regarding digital production and the communication of scientific information across genres.

\section{DIGITAL STUDIO TUTORS AS PARTNERS}

While DS tutors work with faculty, staff, and various university departments, their primary role is to work with individual students or groups of students, filling many of the roles Kim (2015) associated with peer tutors, including:

- supplementing the main course functions in complex skills areas,

- increasing students' opportunities to succeed at the institution,

- improving students' communication skills transferable to professional success, and

- improving public presentation skills.

When working with students, faculty, and staff, tutors inevitably develop their own digital literacy skills. Additionally, DS tutors were active partners in the development of the DS and continue to be so in their own development as tutors. For instance, in addition to crosstraining one another on various technologies during weekly meetings, tutors created and maintain a tutoring manual. Like the manual, trainings are requested by tutors in response to their own needs, and most trainings are developed and delivered by tutors, rather than the faculty director. As the DS tutors work to help other students develop critical digital literacy skills, they also actively work as a team to continue to develop and refine their own digital literacies.

\section{Curriculum development and content delivery in a speech class}

One example of how in-class workshops enabled tutors to partner with students in meaningful ways is evident when examining a speech class taught by one of the Digital Studio's faculty directors. The extended case profiled here illustrates how Digital Studio tutors partnered-with an instructor, students, a CTLE director, and a community partner-to develop a workshop to help students complete a service-learning assignment in the speech course. The assignment asked students to create digital tours for a natural history museum (fall 2016 and fall 2017), a planetarium (spring 2017), and a community organization (spring 2018) located in different states. Tutors maintained involvement with the service-learning project for four consecutive semesters.

In this instance, tutors were engaged as partners in the "enhancement of learning and teaching practice and policy through [both] scholarship of teaching and learning [and] curriculum design and pedagogic consultancy" (Healey, Flint, \& Harrington, 2014, p. 24). Tutors consulted with a faculty member across four semesters, providing valuable input about 
strengths and weaknesses in the professor's project-specific pedagogy and instruction, with their feedback resulting in curricular changes. While the tutors were not students enrolled in the class, they were given opportunities to implement their feedback at the end of each semester in collaboration with the faculty member, wherein they could effectively co-create curriculum. Though this co-construction did not begin at the outset of curriculum development, as recommended by Willis and Gregory (2016), tutors were involved in the development of the DS at the outset and are now involved in any project-specific curricular or pedagogical revisions. This partnership also achieves the goals and upholds the principles of learning communities as described by Healey et al. (2014); in this instance, the learning community is embedded within the course design, with tutors contributing to curricular design and influencing pedagogy (Tinto, 2003).

\section{Fall 2016}

During the fall 2016 semester, forty-seven students enrolled in two sections of the speech class were individually assigned a specific beetle and asked to produce a short informational video about the beetle's flight mechanisms. A DS tutor attended the class, provided and overview of DS services, explained the role of DS tutors to the students, identified how they could assist students in the production of their informational videos, and provided instructions for making an appointment. Students had the option of working with DS tutors to create and edit their videos, and $35 \%$ of students took advantage of working with the DS tutors. Students who worked with the tutors scored at or above the average assignment grade.

After the semester concluded, the faculty member met with tutors to share an analysis of the assignment and discuss the next semester's project. This conversation revealed that some students misinterpreted the assignment, some used low-quality images or images with watermarks, and some demonstrated different levels of understanding about the process involved. DS tutors provided valuable input about how students understood the assignment and about how students approached the process of completing the assignment-information that, in many cases, is unavailable to instructors. Additionally, DS tutors partnered with the faculty member to generate content and strategies for a workshop that could help address these issues.

\section{Spring 2017}

During the spring of 2017, forty-two students enrolled in two sections of the speech class and developed similar videos. To improve the learning experience for students and to enhance the overall quality of the videos, tutors developed workshops on design techniques, production techniques, and storyboarding and delivered them during class time. The workshops oriented students to the project, encouraged students to plan their projects through storyboards and scripts, emphasized the importance of using appropriate materials and citing sources, and provided instruction in various digital design techniques.

After the semester concluded, the instructor met with the tutors to discuss the effectiveness of the workshops. While the workshops resulted in improvements, we concluded that students would benefit from seeing exemplars. Tutors created three videos over the summer to be used as exemplars during the fall. 


\section{Fall 2017}

During the fall of 2017, twenty-two students who were enrolled in one section developed videos on specific birds. A local bird expert spoke to the class about birds, flight, and feathers and answered questions about their specimens. A DS tutor delivered a workshop during class time and showed three exemplars created by DS tutors. Even though one appointment at the DS was required and another was recommended, only ten of twenty-two students had appointments with DS tutors. The average grades for students who worked with the DS tutors were considerably higher (93\%) than the average grades for students who did not (79\%).

At the end of the semester in the meeting with the tutors and instructor, we noticed that requiring outside consultation was not effective. While mandatory tutoring has been shown to improve students' grades and increase students' motivation (Baggett, 2009; Vance, 2016), other students might resent being required to attend mandatory tutoring (Baggett, 2009; Hartman, 1990; Vance, 2016), resulting in a failure to attend tutoring or potentially ineffective tutoring sessions. Some students complied by going to the DS but did not work with a tutor. Additionally, some students self-reported that they overestimated their digital skills and decided not to go to the Studio. We decided that to better help students acquire digital literacy skills, we would have the class meet for two periods in the Digital Studio.

\section{Spring 2018}

In the spring of 2018, twenty-one students in one section created videos. Two class periods were spent in a workshop held in the DS with tutors and the instructor. A tutor gave instructions and demonstrated skills at the beginning of both workshop sessions. Students benefitted by having access to DS technology, allowing them to follow along with the tutor's instruction, and they also had the opportunity to see how other students approached the tasks.

\section{Reflections}

Overall, the major issues identified after each semester were more effectively addressed in subsequent semesters after discussions that emerged with the tutors, demonstrating the partnership between the tutors and the faculty member. One difference noticed by the tutors was that videos produced the first semester did not have multiple layers. Tutors helped students develop their technical skills, so in addition to polishing skills students may have had, the tutors also helped them develop new skills. These included composing multi-layered videos as opposed to one-dimensional videos. For audience members, labels on the screen can increase interest, understanding, and retention of material. Students who had more contact with tutors either through appointments and/or workshops were more likely to submit more effective videos, which resulted in higher mean grades.

Our community partner provided insights through reflection on the project stating that the breadth of product quality increased each semester. She commented that, three semesters previous, videos created by students who had not worked with DS tutors had volume control issues in the audio, which was either too low or varied from loud to soft. Videos also had editing problems. Over time, audio quality improved and fewer editing problems were noted. 
Interestingly, our community partner noted that creativity had not changed over the project. The overall quality of videos became much more polished and professional over time.

This feedback from our community partner indicates that while DS tutors have assisted the faculty member in developing stronger guidelines and have assisted students in mastering the technical skills necessary for creating effective videos through workshops and one-on-one appointments, the tutors have not overstepped their role as tutors by providing creative or content input as students develop these projects. This focus on skills tutoring is in line with literature suggesting that non-subject specific tutoring (such as tutoring in writing or digital literacies) should focus on the tutor's area of expertise (in this case, digital skills) rather than the subject-matter content of the composition (Harris, 1990; North, 1984; Sunstein, 1998). In fact, as Chanock (2002) noted in her reflection on tutoring writing, being unfamiliar with the subject matter of a composition can be beneficial for tutors: "an instructor may have to hold back, when a student comes to ask about a problem with an assignment, because the instructor is in a position to 'hand them ... answers'; the tutor is not, and may be able to help the students to 'find [the answers] themselves'" (p. 122).

Students who had more contact with tutors, either through appointments or workshops, submitted files in the appropriate format, used higher quality images, used fewer images with watermarks, seemed to better understand the process of creating an informational video, and used better editing skills as evidenced by the higher mean grades. As a result of partnering with tutors in the DS, students demonstrated clear academic gains. Students who worked with DS tutors demonstrated high levels of student satisfaction, rating the sessions an average of 4.74 out of 5 on the satisfaction scale.

\section{CONCLUSION}

Positioning DS tutors as partners enhanced the learning experience for the students, the tutors, and for the faculty member. The tutors' skills, knowledge, and approaches complemented those of the faculty member to help students achieve the course learning outcomes, while also allowing tutors and the faculty director to enhance their own digital literacy skills through involvement in the DS. Most significant, though, are the benefits derived from the partnership between DS tutors and the faculty member, which resulted in clear curricular changes, including adjustments to assignment specifications as well as classroom delivery. While implementing workshops seemed to have some benefits for students in spring 2017, the greatest gains in student success were seen in the following two semesters, when students were required to physically attend the DS, either for an individual appointment or through a workshop. Because these workshops were developed at the suggestion of the tutors and in direct response to issues they noticed when working with students during tutoring sessions, it is unlikely that similar curricular and pedagogical changes would have resulted without the tutors' input. Additionally, tutors noted clear gains in their own digital literacy skills, and the faculty partner and DS director have observed significant improvement in the tutors' ability to deliver workshops over time.

The student-faculty partnership discussed in this case study is unique among much of the literature in this area. Although the DS tutors were undergraduate tutors who were not involved in the development of the course from the outset, they were involved in the early- 
stage development of the DS and have been consistently viewed as the digital literacy experts, not only by the students they work with, but by the faculty they work with as well. As a result, not only is the power gap between student and faculty member reduced, the tutors were not troubled by the same hesitancies students might initially experience when partnering with faculty (Cook-Sather \& Luz, 2015).

Our discussion of curriculum in this context falls in line with Fraser and Bosanquet's third category of curriculum, defined as "the students' experience of learning" (p. 272). When redesigning this project, we did not make content changes or adjust the role of this course in the overall program of study. We did, however, change the way that we valued student voices in the development of curriculum. And, because tutors had the opportunity to work with this curriculum across multiple semesters, they were able to better provide feedback from the perspective of both student and instructor. As tutors worked with more students, they were better able to understand the struggles students were having as learners, such as understanding and valuing particular components of the assignment, while also gaining a more nuanced understanding of how the professor could better facilitate learning in certain areas or bridge gaps in students' knowledge.

In their review of Students-as-Partners literature, Mercer-Mapstone et al. (2017) argued that reciprocity "positions both students and staff as having essential expertise to contribute to the goal of furthering education" (p. 14). The DS is an excellent example of the value of reciprocity; in fact, the development and success of the DS would not be possible without the investment of our undergraduate tutors who work alongside faculty and other undergraduate students to support the development of digital literacies across campus. In this way, the development and sustainability of the DS truly represents the "ethic of reciprocity" that is a vital component of fruitful Students-as-Partners initiatives (Cook-Sather \& Felten, p. 179, 2017), with tutors, faculty members, and students participating as co-learners (Healey et al., 2014) and collaborators (Taylor \& Wilding, 2009). Moving forward, we hope that the DS can provide the structure and support necessary for more professors to partner with our undergraduate student tutors in the development of curriculum not only at the course level, but also at a programmatic level.

Our study protocol, 16-095, was certified as exempt by our university's Institutional Review Board (IRB).

\section{NOTES}

1. The terms "functional" and "critical" digital literacies are based on the work of Selber (2004) in Multiliteracies for a Digital Age.

2. Capstone courses are typically offered in the final semester of an undergraduate degree program and are intended to allow students to synthesize the key concepts and skills they developed in their course of study in the production of a final project. Capstone courses may also be called senior seminars or senior theses. 


\section{NOTE ON CONTRIBUTORS}

Dr. Cassandra Branham is an Assistant Professor in the Department of Humanities and Communication and Director of the Digital Studio at Embry-Riddle Aeronautical University, Daytona Beach. Dr. Branham teaches courses in composition, rhetoric, and technical communication, and her research interests include digital communication, digital literacies in higher education, and tutor training.

Dr. Sally Blomstrom is an Associate Professor and Chair of the Humanities and Communication Department at Embry-Riddle Aeronautical University, Daytona Beach. She teaches speech and technical report writing. Her research interests include STEAM literacy, service-learning, and assessment. She includes students in her research teams and values their contributions.

Dr. Lori Mumpower is the Director of the Center for Teaching and Learning Excellence at EmbryRiddle Aeronautical University's Daytona Beach campus. She has published articles on STEM literacy in communication courses and multi-perspective approaches to assessment. Dr. Mumpower is also the founding Director of the Digital Studio, a tutoring space for digital literacies.

Kim Kissh was a tutor at the Digital Studio and also an Aeronautical Science major at EmbryRiddle Aeronautical University. As a recent graduate, she is working her way toward becoming a corporate pilot in the aviation industry. During her time as an undergraduate, when she wasn't in the Digital Studio, she was busy volunteering for Women in Corporate Aviation and Dreams Soar Inc.

Jaclyn Wiley is a graduating senior at Embry-Riddle Aeronautical University, where she has earned a Bachelor's Degree in Spaceflight Operations with minors in Business Administration and International Relations. Ms. Wiley was one of the founding tutors at the Embry-Riddle Digital Studio and remains a dedicated proponent of digital literacy education and tutoring. Ms. Wiley plans to work in the commercial space industry after graduation, helping to propel humanity to great new heights.

Yunxiao Liu is studying Aerospace Engineering at Embry-Riddle Aeronautical University, and he is the Lead Tutor of the Digital Studio (2016-present). He also does product photography and design for a local patch company. In his spare time, he takes pictures as a hobby and plays guitar badly. Yun eventually plans to work in the aerospace industry as an engineer.

Kody Miller is a student at Embry-Riddle Aeronautical University, currently pursuing a degree in Mechanical Engineering with a focus in Robotics. He worked at the Digital Studio as a tutor for two years, teaching countless students how to create professional posters, PowerPoints, and videos. Following graduation, he hopes to further his expertise in the field by going on to graduate school; following that he plans to get involved in the development of modern 
prostheses, creating limbs that are more intuitive and advanced in design and function for those that need them.

Zachary Bryant is a tutor, web designer, and IT professional at Embry-Riddle Aeronautical University's Digital Studio. He is currently studying Mechanical Engineering, with a focus in Robotics. He loves working with computers, and hopes to one day work for Boston Dynamics, creating robots that imitate life.

Brian Reedy is pursuing degrees in both Aeronautical Science and Aviation Business Administration at Embry-Riddle Aeronautical University. Expected to graduate in May 2019, Brian is hoping to fly for an air charter operation in Alaska. In his free time, Brian collects hats and is teaching himself how to play the accordion.

\section{REFERENCES}

Baggett, B. (2009). Improving mandatory tutoring: A mixed-methods program evaluation (Doctoral dissertation). Retrieved from ProQuest. (3403014)

Chanock, K. (2002). How a writing tutor can help when unfamiliar with the content: A case study. The WAC Journal, 13, 113-131.

Cook-Sather, A. \& Felten, P. (2017). Ethics of academic leadership: Guiding learning and teaching. In F. Su \& M. Wood (Eds.), Cosmopolitan perspectives on academic leadership in higher education (pp. 175-191). London: Bloomsbury.

Cook-Sather, S. \& Luz, A. (2015.) Greater engagement in and responsibility for learning: What happens when students cross the threshold of student-faculty partnership. Higher Education Research \& Development, 34(6), 1097-1109. https://doi.org/10.1080/07294360.2014.911263

Fraser, S. \& Bosanquet, A. (2006). The curriculum? That's just a unit outline, isn't it? Studies in Higher Education, 31(3). https://doi.org/10.1080/03075070600680521

Hartman, H. (1990). Factors affecting the tutoring process. Journal of Developmental Education, 14(2), 2-6.

Healey, M., Flint, A., \& Harrington, K. (2014). Engagement through partnership: Students as partners in learning and teaching in higher education. York: The Higher Education Academy. Retrieved from https://www.heacademy.ac.uk/knowledge-hub/engagementthrough-partnership-students-partners-learning-and-teaching-higher

Harris, M. (1990). What's up and what's in: Trends and traditions in writing centers. The Writing Center Journal 11(1), 15-26.

Kim, M. M. (2015). Peer tutoring at colleges and universities. College \& University, 90(4), 2-7. Mercer-Mapstone, L., Dvorakova, S. L., Matthews, K. E., Abbot, S., Cheng, B., Felten, P., Knorr, K., Marquis, E., Shammas, R., \& Swaim, K. (2017). A systematic literature review of students as partners in higher education. International Journal for Students as Partners, 1(1), 1-23. https://doi.org/10.15173/ijsap.v1i1.3119

New Media Consortium. (2016). Horizon report: Digital toolkit. Retrieved from https://cosn.org/sites/default/files/pdf/2016 Horizon Report Digital Toolkit.pdf

Branham, C., Blomstrom, S., Mumpower, L., Kissh, K., Wiley, J., Liu, Y., Miller, K., Bryant, Z., \& Reedy, 148 B. (2019). Digital studio tutors as partners. International Journal for Students as Partners, 3(1). 
North, S. (1984). The idea of a writing center. College English, 46(5), 433-446. https://doi.org/10.2307/377047

Oblinger, D. \& Oblinger, J. (2005). Is it age or IT: First steps toward understanding the net generation. In Oblinger, D. \& Oblinger, J. (Eds.), Educating the net generation. Educause. Retrieved from https://www.educause.edu/research-andpublications/books/educating-net-generation/it-age-or-it-first-steps-towardunderstanding-net-generation

Selber, S. (2004). Multiliteracies for a digital age. Carbondale: Southern Illinois University Press. Sunstein, B. (1998). Moveable feasts, liminal spaces: Writing centers and the state of inbetweenness. The Writing Center Journal 18(2), 7-26.

Taylor, P., \& Wilding, D. (2009). Rethinking the values of higher education: The student as collaborator and producer? Undergraduate research as a case study. Gloucester, England: Quality Assurance Agency for Higher Education.

Tinto, V. (2003). Learning better together: The impact of learning communities on student success. Higher Education Monograph Series. Retrieved from http://www.nhcuc.org/pdfs/Learning Better Together.pdf

Vance, L. K. (2016). Best practices in tutoring services and the impact of required tutoring on high-risk students (Doctoral dissertation). Retrieved from Online Thesis and Dissertations: https://encompass.eku.edu/cgi/viewcontent.cgi?referer=https://scholar.google.com/sc holar?hl=en\&as sdt=0\%2C10\&q=impacts+of+required+tutoring\&btnG=\&httpsredir=1\& article $=1439 \&$ context $=$ etd

Willis, P., \& Gregory, A. (2016). Making the road while walking: Co-creation, teaching excellence, and university leadership. Leadership Foundation for Higher Education. 